\title{
DEL SUJETO AL SUBJECTIL: GENET Y LA DECONSTRUCCIÓN DEL FALOGOCENTRISMO
}

\author{
Beatriz BLANCO \\ Proxecto Derriba \\ beatrizhauser@proxectoderriba.org
}

\begin{abstract}
Avec ce détachement-là, réélaborer, comme problème du seing, de la signature et du nom de la mère, l'alternative $\mathrm{du}$ formalisme ou $\mathrm{du}$ biographisme, l'inénarrable et si classique question du sujet en littérature (Derrida, 1974: 113b).

[...] Ou bien je le dis autrement: l'espace mesuré entre les mots est plus rempli de réel que ne le sera le temps nécessaire pour les lire (Genet, 1986: 16).
\end{abstract}

$\mathrm{E}$ ntre las palabras está el blanco, lo real del texto, que ningún acto de lectura alcanza a relevar. Los blancos -más que el blanco- que marcan el ritmo del texto, su hiato o respiración entrecortada, son lo que resta de la escritura. Derrida ha reinscrito este blanco, (des)trazando los restos de los que emerge como blancura, en su libro de 1974, Glas. En él Derrida introduce la estrategia de la diseminación en una aparente disposición a doble columna que responde a los nombres propios de Georg Wilhem Friedrich Hegel y Jean Genet. La columna que parece tomar a Genet como tema trabaja los blancos, ilegibles de por sí, emergiendo en su pérdida por la operación indecidible de la escritura. Si escribir es trabajar los blancos, hacerlos (i)legibles en su (i)legibilidad, el acontecimiento de escritura Glas no es la emergencia del sentido, sino la imposible emergencia de lo real del soporte; como si el texto fuese los restos de un ensañamiento repetido con la hoja. La columna izquierda de Glas parece tener como tema (sujet en francés) a Genet, a su nombre y a su corpus; erigida junto a la de Hegel -podría pensarse contra ella- discurre a tirones, oscilando de un tema a otro, collage o patchwork de pedazos textuales y discursivos diversos. Fragmentario e inasible, ese ensamblaje escapa a la descripción de una operación 
unitaria e incluso al rótulo del nombre propio Genet. ¿Podemos hablar de la columna Genet, de su columna? Volada desde el origen, no habiendo sido nunca un edificio en pie, se presenta y se deja registrar apenas como un texto; tal vez sea más bien un mecanismo de intervención diseñado ad hoc para embarullar la escritura del Saber Absoluto tal y como se extiende en la columna Hegel. No habría lugar, casa o habitáculo, apenas columna fálica oblicua o truncada en la que morase el nombre propio que, sin embargo, la recorre y la mantiene en pie. Las dos columnas en las que se divide Glas o el glas (tañido fúnebre, clamor en una de sus viejas acepciones) son resueltamente heterogéneas, si bien se cruzan o se solapan en numerosos puntos; su categoría textual no es la misma, si bien ambos textos están extrañamente fragmentados. Si la columna llamada Hegel remeda a ratos la hermenéutica académica, la columna Genet se regocija en la transgresión continua del lenguaje de la academia y de la crítica, duplicando su «objeto». Inasimilable, sin duda, pero muy lejos de una operación hermenéutica o crítica superflua, el corpus de Genet resiste inmaculado, intacto, en Glas; pero a la vez desintegrado por la profusión de las citas que no están ahí para restaurar la palabra del autor. La labor del texto no es restaurar la voz del autor -ya siempre perdida, pues es su falta la que obra texto-, sino responder repitiendo al dejar caer, más que al dar a ver, el resto.

Si comparásemos el modo de citar, el tratamiento y el uso del texto de Genet en el libro de Derrida con la obra ya clásica y en muchos sentidos ejemplar, incluso ejemplarizante, de Sartre, sólo podríamos decir que no tienen nada que ver. En el enorme volumen de Sartre el texto de Genet ocupa un lugar mínimo; el objeto del texto y el texto de ese objeto sólo son llamados a comparecer para testificar a favor del autor como prueba de la verdad del libro. Las citas se insertan armoniosamente para sostener la gran tesis. La operación de Glas es bastante más ensortijada; el texto se encabalga en el de Genet e incluso lo parasita. Los motivos de Glas son, en apariencia, motivos hurtados a Genet, a su vocabulario y a su imaginario (aunque no su estilo, Derrida huye del preciosismo, no intenta imitarlo, más bien le da la vuelta y explora, con la violencia de sus suspensiones y sus exabruptos, su contrario); pero esos motivos idiosincráticos genetianos tejen un texto radicalmente distinto también a los trabajos de Derrida hasta la fecha.

Derrida cita mucho a Genet, quizá demasiado, como él mismo confiesa (Derrida, 1974: 135b, 189b). Las citas proliferan hasta engullir el comentario; pero el comentario parasita las citas, que se suceden trazando caminos extraños y operando, como en el caso Hegel en la otra columna, una completa desfiguración del corpus de Genet, que prolifera indefinidamente transformándose en otro u otros corpus, dejándose catalogar bajo diversos nombres propios, convirtiéndose en testigo, ejemplo incluso, de discursos 
6 Tropelías. Revista de Teoría de la Literatura y Literatura Comparada, 19 (2013) Beatriz Blanco

que inicialmente le habían resistido, como es el caso del psicoanálisis tal como es reinscrito por Lacan. La columna de Genet podría narrar el reverso perverso de las gestas del espíritu y de la dialéctica hegeliana, que traza el espacio mismo de la familia, la casa, al apropiarse de la pérdida absoluta, la muerte; pero la operación hegeliana se describe de ese modo al yuxtaponerla a la operación, ni inversa, ni análoga, de Genet. A la aérea elevación del concepto podría corresponder el vol (vuelo y robo) de la morada familiar y el proverbial desprendimiento genético que haría que no guardase ni sus textos ni su nombre. Sin embargo, esa economía de la pérdida se liga indecidiblemente a su contrario; ambas operaciones y cada una de ellas no se oponen, quizá se remeden -como en la obra de Genet Les bonnes-, se reflejen y se reflexionen, pero sólo quizá (Derrida, 1974: 57 b).

Glas explora la economía del texto, la literatura como trabajo de duelo irremediablemente sujeto al mal de archivo; el nombre propio es el resto de un texto que trabaja para elaborar su duelo. La focalización en la firma explora el lugar donde esta economía encuentra su punto de máxima intensidad. Derrida elige la palabra francesa seing en lugar de la habitual signature. En esa palabra se condensa una de las principales operaciones de desplazamiento y reinscripción del libro, desde el momento en el que seing es homófona a sein (seno) el problema de la firma se reúne con la forcluida cuestión de la madre y el fármacon. La firma devuelve el texto a un nombre, que funciona como elemento externo de organización o al menos de continuidad, y queda como el resto del análisis formal del texto; pero el trabajo de escritura se deja reinscribir como el trabajo de transformación del nombre propio o su expropiación. El «propio» nombre es (re)producido por la economía general del texto hasta llevarlo a su pérdida, al menos, o quizá deberíamos decir ejemplarmente, en el caso de Genet quien, leído por Derrida, transforma su nombre en cosas y lo desparrama a lo largo de sus obras. Derrida remeda la operación de Genet y a la vez la invierte: múltiples nombres propios vienen a ocupar su corpus, su tumba e incluso su ataúd, de los que queda absolutamente expropiado, aprovechando otra casualidad de la lengua francesa por la que genet y genêt son también nombres comunes. En cierto modo, no hay una columna de Genet; hay metamorfosis proteicas de diversos nombres propios confundiéndose entre ellos y con las cosas. Aunque el nombre de Genet resiste o resta hasta el final del libro, donde es desnudado y expuesto en su propia falta; y ese nombre que resta es el nombre de la madre.

El tema de la madre, si bien está ya en Genet, resulta amplificado hasta afectar a la posibilidad de la enunciación, al prejuicio fonocéntrico del sistema de la lengua y al trascendentalista del espacio simbólico. La columna de Genet radicaliza la noción de textualidad general; el espacio simbólico resulta a la vez producido y agrietado por la 
escritura. En esa columna multiforme y proteica Derrida lee a Platón, a Nietzsche, a Mallarmé, prefigura la discusión iniciada un par de años después con Lacan o adelanta temas de los que se ocupará por extenso muchos años después, como el don o el acontecimiento: la capacidad aglutinante de Glas parece ilimitada. Derrida reescribe el texto de Genet implantándole injertos suplementarios, convirtiéndolo en un protético cuerpo de la literatura donde el texto se comenta a sí mismo. Queda por ver por qué eso se hizo en nombre de un Genet del que Derrida no volvió a ocuparse nunca. En principio podría parecer que no había ninguna necesidad, ni nada en su corpus, que diese razón de la tremenda operación discursiva a la que Derrida lo somete. Demasiado fácil resulta admitir que Genet descubre el reverso perverso de la Razón y el Sujeto por ser -de nuevo la cantinela sartreana- un ladrón o un presidiario que glorifica el mal. Derrida y Genet eran amigos; el escritor había abandonado la cárcel, y la novela, hacía mucho tiempo y estaba, en la época en la que él y Derrida se conocieron, completamente entregado a la lucha de los afroamericanos en Estados Unidos y de los palestinos en Israel ${ }^{1}$. Quizá, al nombre de Genet, se llegase desde un deseo o síntoma geográfico y corpo-político. Hay toda una geopolítica del mundo en Glas, del mundo convulsionado de los años 70 que obligó quizá también a Derrida a confrontarse con su origen, al que sólo se llega por el texto.

Es en Glas donde Derrida empieza a trabajar su propia biografía injertándola o yuxtaponiéndola a los textos de Genet y a su nombre. Esa biografía no es el libro de la vida de un sujeto individual, sino el reverso de una gran narración histórica, aunque hace referencia a cierto modo de memoria colectiva. Genet había ansiado la salida del texto, el abandono de la escritura; pero tras Glas volverá a escribir. A mediados de los setenta Genet deja en la editorial Gallimard diversos manuscritos que se afanan en torno a los restos de una memoria no individual, de un yo que contiene, en su falta, los restos de la historia; y al que se llega por la escritura. No hay salida a lo real, pues la realidad tiene la frágil estructura de una memoria ficticia en la que hay que hundirse para recuperar, al menos, los restos. A finales del 2010 esos textos se publican con el título La sentence, suivi de J'étais et Je n'étais pas. La sentence guarda muchas semejanzas con Glas. En primer lugar, su disposición -aunque el de Genet no se organiza en dos columnas, sino que prolifera ampliando y multiplicando los judas, como si radicalizase la presentación sobre la hoja del texto de Derrida -; pero no sólo, pues los cruces con

\footnotetext{
${ }^{1}$ Derrida y Genet se conocieron gracias a su amiga común, Paule Thévenin, fiel cuidadora de la obra de Artaud; y se reencontraron, en 1968, en una convulsa universidad parisina en torno a una mesa en la que palestinos exiliados buscaban apoyo para su causa. En aquella época, cuenta Derrida, solían pasear por un París transformado. Genet había abandonado la literatura en esa época y rechazaba hablar de sus libros. Glas vino después; cuenta Edmund White que a Genet le gustaba el libro por su disposición abierta, frente a la cerrada monumentalización de Saint Genet; el Glas resonó también en la obra de Genet (cf. White, 2005: 713, 796-800).
} 
Glas son bastante más sutiles y complejos. A partir de una anécdota acaecida en el avión, el viaje a Japón se convierte en un pretexto para ahondar en los restos de la llamada civilización judeo-cristiana. Los márgenes del libro dan entrada a los otros o a los rechazados en ella. Las figuras y el lenguaje religioso inundan el texto, que se desenvuelve condensando el tiempo de la narración y la historia en un Je que lo aglutina y lo fisura.

Y el resto que emerge en esos complejos reenvíos textuales se parece vagamente al viejo asunto del sujeto, que en Glas parece elaborarse desde los efectos de firma y la expropiación del nombre. En 1958, en la voluminosa monografía de Sartre, la operación literaria de Genet había sido el modelo de la constitución subjetiva, a partir de una elección originaria fuera de texto, mediante el trabajo literario. La obra literaria era la afirmación del sujeto, la respuesta al orden de los otros, del Otro, a la Ley. Esa respuesta podía ser una respuesta fallida, pues siempre podía correr el riesgo de no resultar legible; pero la hermenéutica fenomenológica y existencial venía en su ayuda para proveernos de las claves del texto, y por ende del sujeto, que en la obra de Sartre funcionaba como una instancia trascendental capaz de sostener el corpus, completo o despedazado.

Pocos autores han generado tanta fascinación por su figura como Genet; firmante y narratario parecen quedar perfectamente identificados para la mayor parte de la crítica; aunque la firma, el nombre, la autoría no son otros nombres para el problema del sujeto, sino los efectos que han podido producirlo en un proceso que es económico. El espectro del Sujeto retorna despojado de sus atribuciones trascendentales, resto del texto. Si la Fenomenología del Espíritu era la narrativa de su constitución, el camino de formación o aprendizaje del sujeto que no era un sujeto individual, sino que por ese proceso alcanzaba la identificación con la generalidad del Espíritu -como en otro sentido lo fue el Hyperión de Hölderlin, aunque no haya en él cierre o reconciliación, salvo en la muerte que desintegra al sujeto a la vez que lo consagra, pero ya no como sujeto-, la obra de Genet podría leerse en el mismo sentido, sólo que en ella el sujeto, por ser un mal sujeto, resulta incapaz de elevarse a la generalidad. La no-historia, la fragmentación radical del texto y del corpus que nos narra Derrida, podría leerse como el anverso de la gesta de la constitución del sujeto, pero un sujeto no ejemplar, sino radicalmente idiosincrático que pervierte el orden social, simbólico, desde el interior, apropiándoselo de modo paródico al repetir el gesto de interiorización-exteriorización relevante. Genet no es sólo la negatividad que no se deja relevar; pues no hay incalculable sin cálculo, ni resto sin orden simbólico. Aunque eso no quiera decir que el orden simbólico detente la primacía sobre el resto, pues queda ahí un efecto incontrolable impidiendo la clausura del sistema, del cual el resto no es condición de 
posibilidad. El je m'éc, extraído de «Ce qui est resté d'un Rembrandt...» y reiterado por Derrida a lo largo de Glas, puede reinscribirse como la dialéctica de Hegel, pero sin Espíritu absoluto, pues éste ha quedado convertido en una figura espectral y, por ello, iterable y singular. El padre, fuente al que retorna la tríada, es el espectro ejemplar, pero desde el momento en el que se presenta como espectro, dislocando la posibilidad de enunciación «aquí y ahora», todo el orden simbólico se pone en riesgo.

El espacio del texto, la escritura sin escena, trabaja en el duelo incesante y après coup del orden simbólico, del metalenguaje, de lo trascendental. El trabajo del nombre es un trabajo de duelo que tiene lugar en el texto indicando en él hacia algo que no es sujeto, ni pura negatividad virtualmente relacional que llegue a ser tal. En «Forcener le subjectile», un artículo sobre Artaud publicado a mediados de los años ochenta, Derrida reinscribe desplazándola la problemática del sujeto en algo que se le asemeja, al menos en lo que respecta al nombre, y que parece funcionar como un archi-sujeto. Sin embargo el subjectil no es un sustrato previo o anterior al sujeto sobre el que, por una operación simbólica, éste se produce, quizá individualidad pre-subjetiva anterior a lo simbólico, previa al Espíritu, como en Hegel el cerebro animal o su cuerpo elevado o elevable al espíritu por la muerte. El cuerpo sigue siendo ese resto en lo simbólico al que el subjectil indica, proyecta o libra emergiendo en el acto de su destrucción. En la reinscripción y la relectura del subjectil hay algo radicalmente heterogéneo, resistente, a la cuestión del sujeto. El subjectil es neutro; no está antes de la sexuación, sino que es lo que resiste a ella imposibilitando la inscripción del cuerpo en la estructura, al igual que gl de Glas, que también escapa a las redes del significante, que no tiene sexo, que arranca el cuerpo y la voz (cf. Derrida, 1974: 262). La historia de la subjetividad no se opone al acontecimiento, memoria del porvenir, marca siempre iterable, temporalidad desajustada; pues el acontecimiento es precisamente lo que no se deja prender en esa historia. La columna de Genet no describe la emergencia del sujeto del texto, ni la política paródica del orden simbólico por parte de un «mal sujeto» que escribe su lengua idiosincrática irreductible al discurso y a la lengua de los otros o del Otro, aunque pueda también haberse leído de ese modo, sino que escribe el resto ya ahí del subjectil, trabajándolo desde la letra.

La reelaboración del problema del autor en el texto de Genet replantea la teoría textual que se había desarrollado en Francia durante la década anterior y lo hace desplazándola desde dentro. Si bien es verdad que su repercusión fue ensordecida, el clamor suena, realizando su fantasma, el fin de una época con algunos años de adelanto. Glas es quizá el libro en el que Derrida lleva hasta el límite las experimentaciones textuales que había compartido con Tel Quel, del que está ya alejado en el momento en el que Glas se publica. Glas no es un libro de filosofía, ni de literatura; es una operación 
radical de escritura que afecta a la lengua como sistema. Pero su propio exceso resulta casi paródico, en este caso la escritura desmonta al texto -si hay tal cosa-, el texto de Genet está ahí para mostrarlo. Glas traza el radicalmente (no)sujeto, mientras que por esa época los telquelianos se ocupaban de recuperarlo junto a la dialéctica. En 1972 tuvo lugar en Cerisy-la-Salle un coloquio dirigido por Phillipe Sollers con el título «Hacia una revolución cultural: Artaud, Bataille». Entre los numerosos participantes no se encuentra Derrida. En el texto que abre el coloquio, con el título «Porque Artaud, porque Bataille», Sollers escribe lo siguiente:

No se trata de socialismo utópico, de inconsciente, de surrealidad, de raspadura hermenéutica, o de problemas de lenguaje. Se trata de dos viejos topos mucho más profundos, dando aquí a este término su sentido de actividad consistente no en minar los cimientos de una sociedad, sino en revolver su propia tierra. Todo lo que se piensa acerca de la sexualidad, el saber, la familia, el habla o la escritura, la representación, la locura es tratado por ellos. Se trata de mostrar cómo, sin pérdida de tiempo, Artaud y Bataille: dos nombres, o mejor, dos gestos que han desenterrado y comenzado a cortar el nudo sometido del sujeto.

El sujeto no esa inesencialidad, esa mancha que provocaría el que existiese por un lado la ciencia y por otro la ideología, de modo que no quedase otro recurso que dejarse dividir y resolver por una e interpelar por la otra. Es la puesta en juego misma de la dialéctica y de lo que ha sucedido desde Hegel, tras Marx y Engels, hasta Lenin y Mao TséTung, para mayor horror de la religiosidad enterrada bajo la concepción de la ciencia (Sollers, 1977: 8-9).

¿Podría verse la elección de Genet, y la inmersión de Bataille en la metafísica, como un desplazamiento del canon telqueliano? El glas, aunque no se agote ahí, podría provenir de Artaud (las glosolalias, el gli/cri) y de Bataille (su poema Glas); y en Glas Derrida desplaza la tópica, y los tópicos, de su tiempo, imponiendo cautela sobre las salidas de la metafísica y las revoluciones en el texto; en lo que quizá se deje leer como una respuesta a las posiciones de Sollers en el grupo Tel Quel. Esa operación o inoperancia, motivo que retorna al menos dos veces en el texto como la mar impasible, es especialmente aguda en la columna de Genet. Las mitologías del texto tocan a su fin; pero al mismo tiempo nunca Derrida había tomado tan radicalmente a la letra la escritura.

En la época en la que Derrida escribe Glas, Genet era ya un corpus textual que había hecho correr ríos de tinta y dado lugar, desde muy pronto, a múltiples aproximaciones literarias; finalmente, él también estaba deformado por las múltiples palabras escritas en su nombre. Genet se había hecho objeto a sí mismo de una operación literaria radical, y no había salido indemne. Buen ejemplo de ello es la edición de sus obras completas en la editorial Gallimard a finales de los 50, siendo aún un autor vivo e incluso joven, precedidas del inmenso tomo introductorio escrito por Sartre e intitulado Saint Genet. ¿Cómo librarse de una canonización al inicio de su carrera literaria? El texto de Sartre hizo mucho daño a Genet, que pasó tras él varios 
Del sujeto al subjectil: Genet y la deconstrucción del falogocentrismo

años sin escribir. Sartre es buen ejemplo, pero no el único; la insistencia en lo biográfico para explicar su obra es una constante en los textos a él dedicados. En 1974 Genet es ya un autor teatral consagrado, pero había dejado de escribir y comenzado sus actividades políticas apoyando primero a los Black Panthers en los Estados Unidos y después a los palestinos. El antiguo presidiario escribió un guión radiofónico denunciando la hipocresía del cierre de los reformatorios y de las discusiones en torno a la pena de muerte. El preciosista Genet, donde las innovaciones literarias estaban siempre presas de un clasicismo de la lengua y un preciosismo del estilo, firmó algunos de los textos más radicales de la vanguardia en sus críticas de arte, muy especialmente el «Ce qui est resté d'un Rembrandt...» publicado en 1967 en la revista Tel Quel. Política y literariamente Genet está vinculado a los grupos de vanguardia entre finales de los sesenta y principios de los setenta; de ese modo entra en contacto con Derrida. Saint Genet está ya muy lejos, pero ha dejado una huella profunda en los textos posteriores; ahí irrumpe Glas. ¿Qué Genet recibe Derrida? ¿Qué efectos tiene Glas en la crítica posterior de Genet? ¿Qué efectos tiene en su objeto Genet, tras afirmar que no hay singularidad genética, que finalmente ese cuasi-libro no se ocupa de Genet? ¿Qué restos produce, a modo de texto, en el corpus que despedaza de ese modo?

De un primer vistazo, el corpus crítico sobre Genet es la reiteración insaciable de su nombre propio. Si bien es cierto que no es un rasgo inhabitual, incluso hoy, de la crítica literaria intitularse a sí misma con el nombre de su objeto, pocos casos hay tan flagrantes como el de Jean Genet. La mayor parte de los textos a él consagrados (y en eso Derrida se recorta como una excepción en el particular claroscuro que produce, y aún más cuando la materialidad del nombre propio parece ser su objeto) se llaman a su vez Jean Genet... ¿Falta de imaginación o manifestación patente de la unión indisociable entre el autor y la obra que esas operaciones críticas presuponen? En esa lista del corpus crítico genetiano abundan las biografías, herencia sartreana sin duda, e incluso los otros textos tienden a desplegarse en ese frágil espacio entre lo literario y lo biográfico $^{2}$. Sin duda ha sido el propio Genet el que ha abierto esa lectura, precediéndola, haciéndose objeto a sí mismo -como desplegará hasta sus últimas consecuencias Glas- y produciéndose a «sí mismo» en un borde indecidible del texto a modo de pliegue. En su prefacio a la bibliografía anotada de Genet, Richard Webb incide y da cuenta del interés que éste despierta más allá de su obra (Webb, 1982: 9). Desde 1947 Genet fue objeto de numerosos artículos firmados por figuras tan relevantes en la Francia del momento como Cocteau, Mauriac o Sartre. Publicado en 1952, Saint Genet comédien et martyr es generalmente aceptado como el trabajo seminal en la

\footnotetext{
${ }^{2}$ Eso se puede observar todavía en obras relativamente recientes (cf. Redonnet: 2000). El autor lleva a cabo una lectura bio-bibliográfica bastante convencional deteniéndose en muchos motivos también tratados por Glas, muy especialmente el duelo en Pompes funèbres, pero no recoge ninguna cita de Glas.
} 
crítica de Genet y discutido en prácticamente todos los libros que tratan de su obra. Su enfoque, que hace depender lo literario de la elección existencial, proporcionó el tono de la mayor parte de los textos posteriores y aún en la crítica reciente sigue despertando polémica (cf. Ringer, 2001). El año de su publicación el libro de Sartre fue ya contestado por Georges Bataille (Bataille, 1957: 185-226). Derrida recoge ambas lecturas en Glas para impugnarlas radicalmente, gesto inhabitual en sus textos. Sartre era una figura muy contestada ya por los círculos de la nueva vanguardia parisina, cercanos a la nueva crítica y al estructuralismo, muy especialmente por el grupo Tel Quel. Bataille, sin embargo, fue un autor reivindicado por el grupo y clave en la formación del pensamiento francés entre las décadas sesenta y setenta (cf. Asensi, 2006: 47-50, 159). Ambos serán duramente cuestionados por Derrida en Glas; aunque en lo que respecta a Bataille algunos de esos rasgos ya estaban presente en «D’une économie restreinte...», Glas los agudiza y el pensamiento de la transgresión y la soberanía oscila aún más hacia la metafísica.

Fuera de las valoraciones a las que la arriesgada operación de Derrida pueda haber dado lugar, y de su carácter de hito en la lectura de Genet, el texto de Derrida no ha tenido demasiados efectos en la literatura sobre él. Quizá porque el discurso de Glas era la puesta en escena de la imposibilidad del metalenguaje y por ende de la crítica. La incomodidad de muchos autores frente a la confusión entre Genet y Derrida o a la fagocitación de su texto no tiene en cuenta los efectos retroactivos que imposibilitan también cerrar el texto firmado por Derrida, pero apuntan ciertamente, si bien para rechazarlo, a un rasgo idiosincrático de la lectura que Derrida hace de Genet, inasimilable para un discurso que trate de fundar su legitimidad como discurso metaliterario.

En cierto modo Genet había proporcionado a Derrida la disposición de Glas; incluso, si esta distinción es practicable, le habría proporcionado su «tema» aparente. La columna izquierda se inicia con algo que parece una cita y que, sin embargo, no lo es estrictamente, pues la producción de flujo en este caso no se deja restringir y los pedazos de texto oscilan. El inicio, entre comillas y en cursiva, refiere a un título de Genet. Parece haber sido extraído de otra parte y colocado en el espacio en blanco que precede al texto. El título-cita se hurta a su condición de elemento unificador del texto que prosigue, que a su vez comienza repitiendo una vez más «ce qui est resté». Esa ensortijada estructura plantea, de entrada, la cuestión del inicio e inscribe al texto en la compleja estructura temporal del déjà, aquí y ahora desajustado por la huella de múltiples espectros: la primera página de Glas describe el Rembrandt de Genet y, a la vez, semeja describir la disposición del texto que escribe al describirlo. La cuasiestructura de esas primeras páginas del libro nos pone sobre la pista de algo que tiene 
Del sujeto al subjectil: Genet y la deconstrucción del falogocentrismo

lugar entre el texto de Genet y ese texto que, en un «aquí y ahora» siempre ya desajustado, Derrida escribió. De algún modo Genet no pre-escribe la forma de Glas, sino que Derrida describe al escribirla su operación sobre él. Al texto de Genet se le han añadido mirillas que lo horadan desde dentro, se le deja proliferar en ocasiones hasta ocupar el espacio blanco que lo mantiene a distancia de la llamada columna de Hegel, se lo cita y recita a modo de patchwork (cf. Derrida, 1974: 7b). El texto de Genet, organizado ya en dos columnas desiguales, empieza a proliferar, a volverse loco por la irrupción de otros textos que lo desajustan desde dentro. Algo así como un acontecimiento ha tenido lugar en el «ce qui est resté»: la introducción o la extracción de un suplemento protético de más, que escapa a cualquier pretensión económica. Sobre Genet, Derrida escribe la lectura/escritura como inscripción de una falta excesiva que está ya ahí desde el origen y el comentario como (re)producción de una prótesis que lo precede y que se extrae del supuesto texto objeto.

La indeterminación de estos pasajes, es más, de toda la operación de reescritura a la que Derrida somete el texto de Genet, pasa por la finta que hace al texto -fingiendo describir otra cosa- contarse a sí mismo su propio modo de composición. El texto es a la vez el texto de Genet y el texto de Derrida, leído anticipadamente por el otro, donde breves imágenes ocupan el lugar de cuasi-categorías que contienen la proliferación imparable y autoinmunitaria del presunto metalenguaje. Tenemos otro ejemplo de esa estrictura cuasi-trascedental en torno a la página sesenta de Glas, donde el escupitajo (glaviaux), arrancado de Genet, proporciona la forma del libro remitiéndonos inmediatamente a la (in)operancia indecidible del resto: el quedar en suspenso del velo o del escupitajo, el tiempo de elaboración del excremento y la indecisión referencial. El texto se moldea a la manera de un excremento, de una secreción, Derrida lo denomina texto glótico:

L'association est donc une sorte de contigüité gluante, jamais un raisonnement ou un appel symbolique; la glu de l'aléa fait sens, et le progrès se rhytme par petites secousses, agrippement et succions, placage -en tous les sens- et pénétration glissante. Dans l'embouchure ou le long d'une colonne (Derrida, 1974: 161b).

Las aglutinaciones no sólo aferran la masa significante, adhieren el sentido; la analogía entre el gladiolo, el escupitajo (glaire) y la espada (glaive) sólo obra texto por un resto de $g l$. El comentario se pega al texto hasta confundirse con él, lo reitera introduciendo a posteriori una prótesis originaria por el trabajo de contrecoupture. Un resto de $g l$ deshace y rehace por el mismo gesto el cuerpo del libro y del firmante. Indecidiéndose entre el soporte, el sujeto, el objeto y la herramienta se deja resonar el subjectil. $G l$ arranca el sexo, el cuerpo y la voz; el género como mecanismo de 
producción de cuerpos diferenciados por un binarismo sexual es el espacio de juego de otra de las figuras que se escurren entre Derrida y Genet, el travesti.

L'incorporation de tous les sexes à la fois -on table encore sur un banquet ou une cène, les poissons sont mangés «presque toujours sans pain ni sel»- suppose la coupure et le supplément à l'intérieur de la double bande. Mais dès qu'en raison de la coupture supplémentaire (la fleur entée), il y a deux bandes, s'agit un double sexe indécidable qui gaine père et mère tout à la fois.

Cette opération économique (économie de la mort indécidable) affecte le linguistique, le verbal, le sémiotique, le rhétorique ou le dialectique, elle n'en dépend pas (Derrida, 1974: 275b).

Extraída de Journal du voleur la figura del travesti condensa los dos sexos, envuelve padre y madre, constituyendo un suplemento en el interior de la double bande. Por haberse nombrado a sí mismos, los travestis de «La criolla» en Le journal du voleur se sustraen a la primera violencia clasificatoria invirtiendo y desplazando los mecanismos de construcción del sexo. El nombre, de la madre siempre, y el seing envenenado provienen de ellas/ellos; la madre, el hijo y el simulacro del padre se confunden en el travesti (transgénero, podríamos decir actualizando el nombre). La caída de la propiedad del nombre abre el espacio donde adviene un cuerpo impropio, que escapa a las leyes del significante que lo constriñe a ser dos. Hay dos, sólo dos, sexos: esa es la premisa del llamado falogocentrismo. Cuando Hegel analiza en la filosofía de la naturaleza el proceso de la sexuación, concluye que hay únicamente dos sexos, que se oponen; si bien para Hegel esa diferenciación que desemboca en oposición es, inicialmente, la diferencia entre lo diferenciado y lo indiferenciado. Un sexo es la inversión del otro, puesto que hay una correspondencia entre las partes genitales de la mujer y las del hombre. En el fondo de esa equivalencia subyace un cuerpo primigenio previo a la partición que, por una oscilación mínima y no deducible, termina jugando a favor del varón y convirtiendo al principio masculino en el principio diferenciado y activo. El travesti traslapa las dos bandas, interseca las dos columnas y se inscribe, de pasada, en el análisis de la feminidad de Kant que Derrida lleva a cabo en la columna contigua dedicada a Hegel. La feminidad es siempre una especie de travestismo, especialmente en el caso de la mujer culta, pues la mujer quiere ser hombre para mejor desarrollar sus designios de mujer, adueñarse de los hombres. El texto kantiano se indecide. La rigidez binaria de los cuerpos sexuados oscila también, en el momento mismo en que los discursos que la dan por sentada o tratan de reproducirla se enredan en una serie de contradicciones internas (cf. Derrida, 1974: 143-149a). El resto que produce y que interrumpe desde los bordes la marcha de esos discursos recibe en Glas nombres diversos, irreductibles al nombre único.

$E l$ travesti traslapa elementos contrarios e interseca tópicas diversas. La escena del travestismo tiene lugar en un espacio indecidible, en un oriente condensado en la tierra 
Del sujeto al subjectil: Genet y la deconstrucción del falogocentrismo

más occidental. Se desarrolla entre el mar y la tierra en una península (presquî̀le). Presqu île resulta homófono de presque il (casi él) redoblando el efecto indecidible entre el espacio geográfico y la asignación sexual. El movimiento del espíritu hegeliano de oriente a occidente se suspende en la parodia del travesti que lo cumple efectivamente. La atópica de travestismo reescribe de otro modo la geografía del espacio colonial y los límites de su representabilidad. El travesti condensa todos los cuerpos dentro de sí, y elabora una geografía no discreta que se mezcla con capas diversas de historias y lugares dando lugar a una corpo-política que deshace la geografía al imprimirle una oscilación indecidible. Entre paréntesis Genet narra la anécdota de su intento de travestirse, situando en Barcelona una escena que habría tenido lugar en Cádiz y que termina con la devolución al mar (mer homófono de mère) de los adornos empleados para ello, metamorfoseados en repugnantes tripas tras su fracaso. Esa escena tiene lugar en una península, lugar ideal del travestismo:

Cette mascarade (quelque part il définit de ce mot la féminité), carnaval entre les deux paranthèses contre-pointées, elle regarde donc à la fois vers 1'Est et vers 1'Ouest, terre et mer, le lever et le coucher du soleil. Tout le monde bande et s'incorpore dans le travesti, les opposés en tout genre, le soleil et les poissons d'un côté, la mer et la nuit de l'autre. «A l'extrême occidental j'avais soudain la synthèse de l'Orient» (Derrida, 1974: 274b).

El travesti concentra en él sexos y regiones, traslapando la dispersión de nombres y temas en el texto. La columna de Genet no es sólo una, ni el texto de Genet, ni el genet/genêt que lo firma; en su corpus se hacen proliferar múltiples nombres y sexos múltiples. El travestismo demarca la geografía de Glas y su cuerpo textual y sexual, trabajando ambos por un mismo gesto y reinscribiendo por adelantado en el trabajo con el subjectil las relaciones entre sujeto e historia.

El corpus de Genet aglutina antes de tiempo el corpus de Glas; ambos se dislocan y trabajan en algo que no es un mero devenir indiferenciado. La lectura encuentra su lugar en los bordes del texto, que resultan ser agujeros aleatoriamente efectuados. Las materialidades significantes mínimas, las chances de la lengua (des)trazan el plano que dibujan los conceptos y la articulación entre los estratos diversos de un texto. El cuerpo sexualmente dividido, indisociable de la lengua, no resta indemne: $g l$ no tiene sentido, ni sexo, y en su trazado ha arrancado también la voz. La escritura de Glas dibuja y se dibuja en el cuerpo del transgénero, que reúne todos los sexos a la vez, que emborrona y reescribe la geografía, por un artificio indumentario que incide en un supuesto real, y que a su vez es extraído y re-injertado en el corpus de Genet produciendo como resto, de pasada, otros textos.

El texto está escandido, cortado, interrumpido por un incesante cuestionamiento de la operación de reescritura. Esos cortes nos recuerdan que la operación sobre las 
obras completas de Genet es una operación violenta, sobre todo porque ese Genet se ha transformado y reescrito metamorfoseándose en flor a través de un acento circunflejo. La prótesis o el injerto como castración son la técnica del texto, no sólo su objeto. El cuerpo de Genet es un cuerpo despedazado: los trozos del genêt re-citados erosionan la monumental reunión de las obras completas. El texto completo disimula una falta que por ese mismo gesto produce. El comentario trabaja sobre pedazos (morceaux), que nunca han pertenecido al todo y que aglutinan mucho más en su grafía. La reescritura de Genet remite a una especie de trabajo de duelo, reincisión sobre lo que ha sido ya hecho pedazos, de sustracción del pedazo y de reproducción sin referencia al todo. El seing suplementario es un seing de más, introducido en el texto en forma de déjà (adverbio en el que resuenan las siglas de Derrida), por ejemplo, que reduce al mínimo o simplemente deja caer la problemática del autor o del sujeto, al hacer resonar la temporalidad desajustada de la escritura intersecada con el tiempo del $\mathrm{Sa}$. La lectura es ya reescritura desde el momento en que el desarrollo del texto sólo puede tornarse legible por medio de una prótesis. La prótesis como estrategia de lectura y escritura es justo lo contrario de la emergencia de un sentido que funcione como matriz trascendental. El efecto trascendental es un injerto, una prótesis suplementaria que abre a la posibilidad de sustitución y a la iterabilidad, constituyendo texto. La prótesis se introduce en el texto de Genet mediante las numerosas figuras que, sin darle ese nombre, remiten a ella (pata de palo, racimo de uvas postizo, acento circunflejo o rosa de estambre) y por su cercanía gráfica con el paréntesis, figuración de la prótesis en el texto. Si la prótesis se introduce en Genet por medio de las escenas narradas en su texto, el paréntesis se extrae y se recose de nuevo.

Esa retorcida estrictura pone en juego una economía auto-inmunitaria, una gráfica del archivo y del duelo, un exceso primario a posteriori que produce la falta y se produce como falta. El reste diseminado se desliza describiendo al tex to que se escribe a su vez, se (re)produce, al sustraerse o insertarse, con los nombres de prótesis, paréntesis, injerto, fetiche, tras las marcas de la geografía atópica del travestismo. El texto ni siquiera se finge comentario; la lectura se confunde con una escritura que lo despedaza todavía más por medio de injertos, de la prótesis, paréntesis, tmesis, mirillas, suspensiones, extracciones; pero esa serie no agota, si es que lo cerca, el objeto de la obra. Los intentos de reducirlo a una tesis fracasan; a la tesis se le añade el exceso de un «pro» que la transforma en otra. El cuerpo textual de Genet no es objeto de una lectura, sino de una reescritura que trabaja sobre el subjectil, remarcando su indecisión. En el subjectil, forma y contenido no se distinguen, como no se distinguen el texto que se lee y el texto que se superpone para comentarlo. Si el subjectil puede dar cuenta del «Genet» de Derrida après coup es porque en él se incide en un supuesto soporte que no se diferencia de la operación sobre él. En el subjectil suena como carne el fin de todo 
Del sujeto al subjectil: Genet y la deconstrucción del falogocentrismo

supuesto metalenguaje. Esa operación no es una subida del fondo a la superficie, o a la inversa, sino más bien la producción de un agujero y de una falta en la superficie antes lisa e inencentada. La inscripción pertenece a la economía del resto; la escritura es siempre injerto de más, prótesis suplementaria.

\section{Bibliografía}

ASENSI, M. (2006): Los años salvajes de la teoría. Valencia, Tirant lo Blanch.

BATAILLE, G. (1957): «Jean Paul Sartre et l'impossible révolte de Jean Genet», en La littérature et le mal. Paris, Gallimard.

DERRIDA, J. (1967): L'écriture et la différence. Paris, Seuil, 1967. (1972a): La dissémination. Paris, Seuil.

- (1972b): Marges de la philosophie, Paris.

- (1974): Glas, Paris, Galilée.

- (1986): «Forcener le subjectile», en THÉVENIN, P. ed., Dessins et portraits d'Antonin Artaud. Paris, Gallimard.

- (2001): «Le papier ou moi, vous savez...», en Papier Machine. Paris, Galilée.

GAITET, P.(2003): Queens and Revolutionaries: New Readings of Jean Genet. University of Delaware Press.

GENET, J. (1953): Pompes funèbres. Paris, Gallimard. (1968): «Ce qui est resté d’un Rembrandt déchiré en petits carrés bien réguliers et foutus aux chiottes», en Oeuvres complètes, vol. 4, Paris, Gallimard, 1968.

— (1979): «Le secret d'un Rembrandt», en Oeuvres complètes, vol. 5. Paris, Gallimard.

- (1986): Un captif amoureux, Gallimard, Paris. (1996): Journal du voleur. Paris, Gallimard. (2010): La sentence, suivi de J'étais et Je n'étais pas. Paris, Gallimard.

NUNEZ, L. (2010): «Une sentence inédite», Le Magazine Littéraire, 503, p. 83.

REDONNET, M. (2000): Jean Genet: le poète travesti. Paris, Grasset.

RINGER, L. (2001): Saint Genet Decanonized: The Ludic Body in Querelle. Rodopi, Amsterdam.

SARTRE, J. P. (1954): Saint Genet. Comédien et martyr. Paris, Gallimard.

SOLLERS, P. ed., (1977): Artaud. Valencia, Pre-textos.

WEBB, R. (1982): Jean Genet and his Critics: An Annoted Bibliography 1943-1980.

The Scarecrow Press, Metuchen, N. J. and London.

WHITE, E. (2005): Genet. Barcelona, Mondadori. 